\title{
LA INDUSTRIA ARTÍSTICA EN EL ENTORNO TRANSMEDIA DE LAS REDES SOCIALES. PRIMERAS APROXIMACIONES ${ }^{1}$
}

Pilar Irala-Hortal

Universidad San Jorge

Data recepción: 2018/09/21

Data aceptación: 2019/05/07

Contacto autora: pirala@usj.es

ORCID: https://orcid.org/0000-0003-1385-2475

\section{RESUMEN}

El presente trabajo es una primera aproximación investigadora a cómo la industria artística (producción, exhibición, difusión crítica, distribución, venta) ha encontrado un lugar natural de trabajo, colaboración, ejercicio crítico y transacción comercial en el mundo digital y, de forma muy importante, en las redes sociales. Esto ha llevado a diferentes transformaciones y adaptaciones del mundo del arte al universo digital. Las conclusiones más destacadas se concentran en uno de los cambios que podrían ser más evidentes y profundos, esto es, la influencia creciente del usuario en toda la cadena de la industria del arte. Antes de la revolución digital quien controlaba la producción (mecenas) o la información (intermediario) controlaba en gran medida el éxito de un artista, un escritor o una revolución. Pero, gracias en buena parte, a las redes sociales y a las relaciones transmedia con las que están interconectadas, esta escala ha variado y, en ocasiones, se está invirtiendo.

Palabras clave: transmedia, redes sociales, arte, creación, difusión

\section{ABSTRACT}

This paper analyses how the art industry (production, display, critical dissemination, distribution, and sale) has found a natural place for work, collaboration, critiquing and commercial transaction in the digital world and, specifically, in social media. This has led to differing transformations and adaptations of the art world to the digital world. The most notable conclusions focus on one of the most evident and profound changes, namely the growing influence of the digital user throughout the art industry chain. Prior to the digital revolution, whoever controlled production (the patron) or information (the middleman) largely controlled the success of an artist, writer or revolution. But thanks in large part to social media and the cross-media relations it is interconnected with, this scale has changed and is, on occasion, being inverted.

Keywords: cross-media, social networks, art, creation, dissemination

\section{Introducción: La semiosfera transmedia}

La relación del arte con las nuevas tecnologías es muy dilatada en la historia de la humanidad, y es incluso más extensa cuanto más amplia sea la definición de tecnología. No es extraño, por tanto, que el arte encuentre nuevos paisajes de expresión y expansión en las tecnologías sociales que más rápido están cambiando y evolucionando en la contemporaneidad, y que son las que se refieren a las redes de conexión entre personas. Nos encontramos en un momento histórico y so- 
cial novedoso y que está, además, en continuo cambio y avance. Muchos son los teóricos que en las últimas décadas del siglo XX ya reflexionan sobre los cambios, no solo visuales sino también tecnológicos, que estaban por llegar casi inmediatamente. Ejemplo de ello, entre los muchos que tenemos, es Mirzoeff quien ya en 1999 afirmaba que "vivimos en la pantalla"

Vivimos en la pantalla-ventana, en internet, en la conexión continua y en la imagen. No solo porque la tecnología nos lo permite, sino porque el ser humano ha desarrollado diferentes medios técnicos y tecnológicos que facilitan hacer lo que siempre ha hecho de forma instintiva, es decir, comunicarse. $Y$, en cierto modo, ha regresado a nuestra primigenia forma de comunicación: la visual. De las rudimentarias estrategias de comunicación del paleolítico hasta las pantallas del smartphone, el ser humano ha usado la imagen para comunicarse dentro de la comunidad y entre culturas. No es extraño que las aplicaciones digitales que se han desarrollado, que existen y que están en planificación se centren, fundamentalmente, en la imagen.

El cambio más profundo y fundamental es que se han transformado, o al menos se han ampliado y mezclado, los roles. Los encargados de crear y controlar la comunicación en general y la imagen en particular eran, antes de la revolución digital y de la interconexión, aquellos que controlaban también el poder y la cultura. Pero, en la actualidad, esto ha cambiado. Son muchos los autores que han reflexionado sobre estos cambios. Desde Juan Antonio Ramírez ${ }^{3}$ L Lipovetsky, Eco o Tisseron $^{5}$ las transformaciones en las relaciones entre productor, intermediario, emisor y espectador en la contemporaneidad aparecen analizadas desde diferentes perspectivas y enfoques ${ }^{6}$.

Por otro lado, no solo se trata de digitalizar las relaciones, sino de la llegada de una revolución transmediática, tal y como teorizó, avanzó y codificó Jenkins. El término "transmedia" se refiere a dos géneros narrativos diferentes cuando hablamos de ficción o de no ficción. En los productos de ficción el vocablo se refiere a la difusión de contenidos a través de diferentes medios: $t v$, internet, cómic, videojuegos, libros... Cada uno de esos medios o plataformas aportan novedades narrativas al conjunto, es decir, se puede ver un capítulo de la serie en la televisión, pero en el videojuego la acción continúa de otra forma y así sucesivamente. En este caso, el espectador/lector/jugador es también guionista. No hablaremos aquí de la no ficción ya que el presente trabajo se centra en la creación artística que, aunque puede referirse a un objetivo y producto documental, se escapa de los límites de esta investigación. Para María Mattei ya no hay límites ni siquiera en lo que ella denomina el "'espacio de observación' del 'espacio performativo', sino que se concentra [la semiosfera] en un único público performer"

Así, Henry Jenkins trasladó el término "transmedia" al ámbito de la narrativa audiovisual de ficción en 2007 y, posteriormente, otros teóricos como Carlos Scolari, las han acotado o han aportado nuevas características. Siete son las particularidades de los productos transmedia para Jenkins. Las expuso en un artículo de 2007 en el que ya planteaba algunas cuestiones básicas tales como la sistematización en la difusión de estas piezas en las diferentes plataformas, y la importancia del esfuerzo en coordinarlas las sinergias con la industria mediática o las diferentes aportaciones de cada plataforma ${ }^{\text {. }}$ Posteriormente publicó sus siete principios de la narrativa transmediática para la ficción?.

Se puede encontrar el mismo razonamiento transmediático en una pieza periodística, en un producto de ficción o en la obra de una artista, porque lo transmediático es un sistema de pensamiento, creación y relación. Es decir, centrándonos en el arte, un artista está presente en varias redes sociales entre las que habitualmente se encuentran Instagram y Pinterest por su sistema de comunicación y relación entre usuarios basado en la imagen, además de Facebook, Youtube y la propia web del artista. Esta es una de las características de la vida transmedia: la multipresencia en diferentes redes y lugares de internet, con una misma personalidad (el artista) y que usa de forma coordinada dichas redes: elige unas plataformas para mostrar su trabajo final (por ejemplo Pinterest $\left.{ }^{10}\right)$, en otras puede presentar además el desarrollo creativo (generalmente para esto elegirá Instagram"1, por su inmediatez o Youtube ${ }^{12}$ ) y en otras venderá su obra (por ejemplo en Artsy 13).

Jenkins no solo ha sistematizado el término "narrativa transmedia", sino que, a la vista de los 
autores y multiplicidad de reflexiones que se han sumado a las suyas desde 2007, el propio Jenkins matizó en 2011 lo siguiente:

Transmedia, used by itself, simply means 'across media'. Transmedia, at this level, is one way of talking about convergence as a set of cultural practices. Keep in mind that Marsha Kinder in Playing with Power wrote about 'transmedia intertextuality', while I was one of the first to popularize the term, transmedia storytelling. Transmedia storytelling describes one logic for thinking about the flow of content across media. We might also think about transmedia branding, transmedia performance, transmedia ritual, transmedia play, transmedia activism, and transmedia spectacle, as other logics. The same text might fit within multiple logics ${ }^{14}$.

\section{Material y métodos}

Por un lado, se han estudiado las aportaciones de Jenkins bajo la perspectiva del arte. Así, se han analizado diferentes propuestas artísticas bajo las características transmediáticas aportadas por dicho teórico y se aportan aquí aquellas cuestiones que ayudarán a trazar la relación entre unas y otras. Por otro lado, se han cotejado dichas características transmedia con las propuestas en las redes sociales ${ }^{15}$ pertenecientes a la cadena de la industria cultural, específicamente del arte, y se ha comprobado cómo han afectado las redes y su relación transmediática al ámbito de la creación, difusión, exhibición y venta de la obra.

Las características que aporta Jenkins ${ }^{16}$ para los productos o acciones transmediáticas se adecuan no solo al producto audiovisual, sino también a cualquier producto artístico: 1 . Spreadability vs. Drillability; 2. Continuity vs. Multiplicity; 3 . Immersion vs. Extractability; 4. Worldbuilding; 5. Seriality; 6. Subjectivity; 7. Performance. Estas características han sido relacionadas por varios investigadores, incluyendo el propio Jenkins, con el concepto de inteligencia colectiva definido por Pierre Levy. La idea fundamental que reside en este concepto es el del enciclopedismo universal e interconectado. Es decir, todo el conocimiento humano no puede ser conocido por una única persona, quizás ni siquiera por una comunidad, pero sí reside en la red, allí está todo. Levy apuntaló y explicó la inteligencia colectiva en la investigación que le encargó el Consejo de Europa sobre la influencia, o más bien, las "implicaciones culturales de las nuevas tecnologías de la información y la comunicación (TIC) digitales"17.

Las consecuencias del desarrollo de la comunicación transmediática en el universo visual son enormes, tal y como apunta Ródenas' ${ }^{18}$, ya que nuestro mundo es eminentemente visual, y no solo nuestra sociedad lo es, sino que lo han sido también nuestras formas primeras y más habituales de comunicación e interrelación social. El presente estudio tiene unos límites más pequeños y no nos ocuparemos de ahondar en este concepto, pero sí debemos indicar la idea de que la interconexión virtual, visual y social forma parte de un proceso mucho mayor que el transmedia o, bajando más a lo concreto, del uso de las redes sociales por parte de los artistas.

\section{Sobre lo transmediático en el arte}

Los nuevos márgenes creativos y divulgativos de la ficción sirven para explicar los nuevos márgenes de la creación gracias a las nuevas tecnologías y, sobre todo, a internet 3.0 y 4.0. A la luz de lo planteado más arriba expongo a continuación cómo dichos rasgos han creado nuevos límites para la industria artística.

Cuando Jenkins hace referencia al spreadability y drillability, se refiere a que es de amplia o fácil difusión y que además fomenta la profundización en el tema. Si analizamos estos factores en relación a Instagram, u otras redes, y el arte nos damos cuenta de que hay varias fórmulas en las que el público puede ejercer esta difusión de la obra. Lo más inmediato y habitual es el "me gusta", de tal manera que otros usuarios, seguidores tuyos, pueden interesarse por la obra y visitarla. También es posible enviar un mensaje privado enlazando el post o hacer comentarios con hashtag y con la inclusión del sobrenombre de otros usuarios.

Los conceptos de continuity y multiplicity se refieren a la continuidad narrativa entre medios y su capacidad de multiplicar(se) hasta el infinito. Así, podemos ver estos rasgos en un artista que ha creado una amplia comunidad de seguidores, también en las redes sociales: Ai Weiwei. El artista chino tiene perfil en Facebook donde tiene gran cantidad de seguidores y en una sola semana 
puede tener varios miles de "me gusta". Así, el 14 de mayo de 2019 había superado ya los noventa mil likes y, es esa misma fecha, tenía en su Instagram más de 507 mil seguidores.

En ambos perfiles publica fotografías, vídeos y diversas iniciativas que Weiwei está realizando sobre los migrantes que huyen de Siria, pero también otros proyectos. En ambas plataformas Weiwei publica sobre estos temas, pero en Facebook incluye vídeos y tiene una actividad más regular, mientras que en Instagram selecciona más cuidadosamente lo que publica y suelen ser fotografías más reposadas. Tanto Facebook como Instagram son complementarios del trabajo de Weiwei y difunden su trabajo en la continuidad de una plataforma sobre la otra, y con la multiplicidad que permiten los seguidores de ambas aplicaciones.

Otras características son immersion y extractability, es decir, seguir la experiencia desde una perspectiva personal a través de la inmersión o profundización en el entorno de un artista y la posibilidad de extractar o extraer informaciones cruzadas. Se consigue cuando el público tiene la posibilidad, por ejemplo, de localizar dónde está o dónde se realizó la obra del artista, o dónde será su próxima exposición. Esto permite al público localizar un lugar exacto relacionado con la obra de arte, informarse sobre ese lugar, quizás ir a conocerlo, etc. Por tanto, no solo se consigue la inmersión más allá de la obra terminada, sino que el seguidor del artista puede hacer un viaje hasta la galería o el lugar donde se hizo la obra, incorporándolo así a su vida cotidiana o historia personal.

Bansky, por su parte, consigue reunir en el uso que hace de las redes sociales tanto el worldbuilding o construcción de universos, como el concepto de subjetivity y el de performance. Es decir, ahondar en el contacto directo con el espectador a través de una experiencia subjetiva que, en algunas ocasiones, puede llegar a la interactividad directa a través, por ejemplo, de acciones físicas y públicas. Bansky no solo realiza sus famosos grafitis, sino que tiene redes sociales en las que se publican sus obras, pero también tiene merchandising ${ }^{19}$ e incluso montó un antiparque de atracciones ${ }^{20}$. En este caso también el concepto de seriality se puede aplicar a este artista y su uso de las redes.

Además, podemos encontrar también en las redes y en su interconexión transmediática un ejemplo de acción artística que imita la inteligencia colectiva o, al menos, personifica el todo por la parte. Es el proyecto de Ascensión Amaro al encarnar la metáfora del conocimiento extendido. Esta profesional se presenta como una exgalerista que comenta obras y artistas emergentes. Pero en realidad no se trata de una persona sino de un grupo de profesionales del arte contemporáneo que, bajo la personificación de Ascensión Amaro, pasaron un año (2013-2014) seleccionando y analizando obras de arte que se sitúan en los márgenes de lo oficial. Ellos mismos explicaron que su proyecto busca "analizar las posibilidades de las redes sociales como instrumento de comunicación, conocimiento y difusión del arte contemporáneo y al mismo tiempo como plataforma de creación en sí misma"

Ascensión Amaro aún mantiene presencia en las redes (Facebook e Instagram) y tuvo varios proyectos editoriales para la difusión y la crítica de arte, como por ejemplo la revista TenMag o la Plataforma de Arte Contemporáneo. Esta acción da idea de cómo las redes sociales del arte participan del complejo universo interconectado de la inteligencia colectiva y, en cierto modo, juegan con él.

\section{a. Sobre la creación}

Cómo se pueden distinguir las obras de valor estético y peso artístico de los meros ejercicios expresivos no profesionalizados. Algunos teóricos afirman que este margen se está difuminando tanto que es muy complicado marcar verdaderos límites. Cualquier usuario puede comenzar una trayectoria personal en el arte y, por sí solo, invirtiendo tiempo y esfuerzo en los contenidos o usos transmediáticos puede tener oportunidades reales en la industria cultural y artística. Existen, en este sentido, proyectos como Internet is site specific, comisariado por Nosotros, una "plataforma online de investigación, práctica y teórica, sobre arte contemporáneo" 22 .

Como explican desde la propia revista, este proyecto se mueve en dos aguas: la editorial y el comisariado. Lo que hacen es entregar el con- 
trol total de la cuenta oficial de la revista a un artista o colectivo durante un tiempo estipulado, generalmente una semana, durante el que le dan libertad total. Lo más habitual es que los artistas cuelguen obra fotográfica, imágenes y vídeos de sus obras. Pero este proyecto colaborativo, a modo de cadáver exquisito surrealista, va más allá de la creación artística y acaba siendo más un escaparate para el conocimiento de los artistas seleccionados, algunos emergentes.

Existen también proyectos, o fórmulas, que son recetas tanto para artistas como para todos aquellos usuarios de las redes sienten que tienen un lugar para ejercer su creatividad. En esta categoría están los proyectos \#365. Se trata de publicar una fotografía cada día durante un año. Miles de personas, no solo artistas en el sentido profesional del término, han seguido esta receta. Pero entonces qué sucede con el arte como icono, como símbolo o como sueño. Para Mattei ahora el "poder de las imágenes es un campo de fuerzas de doble dirección. La dirección centrífuga del icono imagen visible, que reenvía continuamente a algo diferente de sí mismo, y la dirección centrípeta del ídolo aglutinador, que requiere veneración, suscita pasiones y que no acepta, en su calidad de imagen revelada, la comparación ni la selección paradigmática entre otros textos." 23

Si los límites son tan difusos, pero el poder de la imagen ha crecido tanto exponencialmente, no es extraño que algunos de los proyectos artísticos más comentados y seguidos de los últimos años en Instagram sea, precisamente, un ejercicio creativo entre la performance, el voyerismo y el icono clásico, como es el caso del proyecto de Amalia Ulman donde se juntan el impacto persuasivo de los selfies, el divinismo, el ensueño fílmico y el surrealismo de la mentira ${ }^{24}$ y sigue la estela performativa de Cindy Sherman.

Lo que nadie sabía es que todo era mentira. Fue un proyecto bien planificado cuyo punto de partida y, sobre todo, de llegada fue la idea de mujer y femineidad en la sociedad contemporánea, concepto que, según explica Ulman en una entrevista que el crítico Alastair Sooke le hizo para el The Telegraph: "'It's more than a satire', she explains. 'I wanted to prove that femininity is a construction and not something biological or inherent to any woman. Women understood the performance much faster than men. They were like, 'We get it - and it's very funny.' What was the joke? The joke was admitting how much work goes into being a woman and how being a woman is not a natural thing. It's something you learn" 25

Este trabajo en Instagram y para Instagram ha alcanzado fama, no solo entre sus seguidores, sino en el mundo del arte fuera de las redes. Su presentación tuvo ya un entorno de lujo ya que fue una actividad dentro del programa New Museum New York's First Look Program en octubre de $2014^{26}$. Varios críticos de arte como el ya citado Sooke, y revistas de arte han calificado este trabajo como una obra maestra. Incluso la revista Forbes la nombró en un artículo acerca de las personas más influyentes menores de 30 años $^{27}$. Y, además, galerías de reputación internacional como la Whitechapel Gallery y la Tate Modern la alaban'28.

Así, Excellences \& Perfections es un buen ejemplo en el que se manifiesta el dinivismo del que habla Mattei: "[...] el divinismo se presenta como un fenómeno de profundo interés para la semiótica visual, construido sobre parejas de oposiciones como las de público/privado, notoriedad/ anonimato y sobre todo ser /aparentar, que en un contexto visual es declinable según la dicotomía secreto/transparencia" 29. Tanto para Mattei como para Ulman las razones del éxito de este proyecto es haber conseguido involucrar al público, haber creado o mantenido una audiencia cautiva tanto por hacer cercana la vida de un desconocido como por el hecho de que en esa vida se encuentra el drama. Mattei lo explica de esta forma "¿Qué es entonces lo que sigue marcando la diferencia? Una vez más, la narración, el cuento ganador que atrae al público: contar una historia que tenga un entertaiment value y un drama, es decir una parte humano/identificativa y otra mítico/proyectativa que será amplificada (retuiteada, publicada, compartida)[...]" ${ }^{\prime 30}$. Y Ulman, por su parte, admite que triunfó "ofreciendo el contenido más entretenido: otro drama humano." ${ }^{31}$

Otros proyectos fotográficos creados para las redes sociales presentan un enfoque de creación colectiva. Por ejemplo, Applifam ${ }^{32}$ es un colectivo nacido en 2011 cuando Johan Du Toit publicó 
en Instagram una fotografía e invitó a que cualquiera pudiera bajársela y editarla, manipularla y volverla a subir a la aplicación con el hashtag \#applified_jvdt. Comenzaba así una pionera acción cultural, colectiva y abierta que crecería con gran velocidad y cuyos ingredientes básicos eran la fotografía, la edición abierta y la publicación en Instagram. Cada día se publicaban una fotografía original (y su política solicitaban que solo se subieran fotografías propias y originales) y durante 24 horas los participantes podían hacer obras derivadas. Applifam tenía en 2018 miembros de 22 países y superaba ya los 10 mil usuarios 0 artistas implicados ${ }^{33}$. Es quizás el colectivo de artistas más grande de la historia. Gracias a las tecnologías de internet 2.0 y 3.0, al intercambio de información y a la mediaesfera transmedia el tradicional grupo de artistas reunidos en un estudio es ahora una red de creadores mundial. Este colectivo o comunidad digital ha tenido también varias exposiciones físicas.

\section{b. Sobre la difusión de la obra y del artista}

Instagram no es solo una herramienta para que los artistas trabajen con ella como un medio o como materia en sí misma para sus proyectos o como mero escaparate, sino que es también una plataforma que tanto instituciones públicas como privadas usan para presentar a sus artistas y obras. Algunas de las instituciones más importantes como el MOMA tienen proyectos museográficos específicos para Instagram, sobre todo invitando a los instagramers (usuarios de Instagram) a participar en exposiciones. Entre las instituciones internacionales más activas se encuentran el Museo del Louvre (@museelouvre), el Museo de Arte Moderno de Nueva York (@themuseumofmodernart) o la Tate Modern (@tate).

Entre las acciones llevadas a cabo por instituciones de renombre se encuentra la que desarrolló el Columbus Museum of Art que invitó a su público a tomar fotografías de la vida diaria, en homenaje a la New York City's Photo League, una de las primeras agrupaciones de fotógrafos artísticos que en los años 30 y 40 del siglo XX tomaban imágenes de la cotidianidad. Se enviaron más de 45 mil imágenes, de 5 mil fotógrafos de 89 países. El hashtag del proyecto, \#MobilePhotoNow, fue seguido por más de 36 millones de personas. Según los datos que se dieron en la conferencia anual sobre museos y web en 2015, el evento llegó a más de 270 millones de personas en todo el mundo entre participantes directos, visitantes presenciales y virtuales y la cobertura mediática ${ }^{34}$.

Algunas instituciones relacionadas con el arte contemporáneo usan su cuenta de Instagram para difundir noticias o dar información sobre los artistas y sus obras. Entre las instituciones que más rápido comenzaron a hacerlo se encuentran el San Francisco Museum of Modern Art y el Brooklyn Museum, en Estados Unidos ${ }^{35}$. Como afirman las investigadoras Georgia Marcelino y Marián Morena ha comenzado un replanteamiento de la relación del museo o centro de arte con su público, sobre todo en la consolidación de las relaciones directas entre ambos y buscando la participación del visitante. Para ello, un elemento fundamental ha sido "la integración de las redes sociales como parte de su plan de comunicación y difusión ${ }^{\prime 3}$. Aunque las investigadoras también matizan que todavía queda un largo camino por recorrer, no solo porque muchas instituciones no usan las redes sociales sino porque las que las usan lo hacen, en general, de una forma poco innovadora dando solo información y sin aportar una verdadera dinámica con el público.

Los centros para el arte contemporáneo más pequeños parecen ser los más innovadores con las tecnologías. Quizás sus presupuestos más ajustados sean un aliciente para organizar talleres y exposiciones con estos enfoques. Por ejemplo, la Sala Fundación Cruzcampo organizó en 2015 la exposición Infinito Particular, una exposición de 250 instagramers activos. La muestra, producida por la sala y organizada por el estudio "La madre de los Beatles" en concurso público, se justifica porque "Instagram tiene la capacidad de convertir cualquier momento, por pequeño e insignificante que sea, en algo trascendente, susceptible de ser comentado y compartido" ${ }^{37}$.

También existen instituciones nacidas al abrigo de Instagram. Es el caso de Instagramers Gallery, fundada por Phil González y Jorge Martínez ${ }^{38}$. Todo comenzó cuando en 2014 González y Martínez comenzaron a seleccionar las mejores fotografías del día y a premiarlas con mil dólares y el título de "mejor fotografía del día". La iniciativa creció y han llegado a entregar premios inter- 
nacionales de 100 mil dólares. Además, realizan talleres, charlas y encuentros ${ }^{39}$. No solo se trata de una galería virtual, sino que comenzaron a abrir sedes físicas (Miami y Madrid).

No solo eso, sino que han desarrollado una aplicación que lleva su mismo nombre para ayudar a encontrar los usuarios para que colaboren entre ellos. A pesar de su vocación universal esta app solo estaba disponible para IOS. Entre los ejemplos de Instagram "creator" está Lucas Levitan con un trabajo que se basó en la "fotoinvasión" 40. En 2014 presentaron su proyecto en versión europea y fue Madrid la ciudad elegida para lanzar la iniciativa en todo el continente, en la Fundación Telefónica. La web invita a los usuarios a postularse para exponer en la galería. Cuando llegó el proyecto a Madrid se trataba de una serie de actividades temporales, pero ya han pasado a formar parte de la actividad habitual del centro y se han instalado en el segundo piso de la Fundación Telefónica ${ }^{41}$.

\section{c. Sobre la venta y actividades relacionadas}

Instagram también amplía las fronteras en la venta de arte, es decir, también hace del comercio artístico una acción transmediática. Existen aplicaciones específicas como Artsy que desde su plataforma online se dedica no solo a la exhibición y difusión de arte, sino también a las subastas, a la educación y a la investigación a través de su proyecto The Art Genome Project ${ }^{42}$. Pero Instagram es usada también por casas de subastas y galerías para realizar sus ventas. En el informe sobre las instituciones del arte y las nuevas tecnologías que publicó el Pew Research Center en 2013 ya incluía a Instagram entre las herramientas usadas solo dos años después de su nacimiento.

Aunque es cierto que Facebook encabezaba la lista a la que le seguía Twitter ${ }^{43}$ y Youtube, lo cierto es que el posicionamiento de Instagram ya indicaba la fuerza que en 2012 (el informe es de enero de 2013) la aplicación comenzada a tener en el mundo del arte y sus instituciones ${ }^{44}$. Este informe evidencia que ya en 2012 las instituciones del arte habían conseguido muchos beneficios gracias al uso de las diferentes redes sociales. Instituciones internacionales en la venta de arte como Christies's y Shotheby's usan Ins- tagram para presentar, difundir y aumentar las ofertas sobre sus piezas ${ }^{45}$.

El informe afirma que se incrementaron los asistentes, se vendieron más entradas, aumentó el número de personas que conocían a la institución y también la facilidad para organizar y fortalecer los esfuerzos en la búsqueda de fondos $^{46}$. Además, el informe indica otros usos que las instituciones hacen de las redes en general, pero también de la presencia online como las posibilidades de acceso al programa de la institución desde el móvil o venta de productos. Así, el $15 \%$ de las instituciones que formaron parte de la investigación usaban las aplicaciones móviles para vender entradas o servicios ${ }^{47}$. Y es un dato importante si tenemos en cuenta que este informe se realizó sobre 1258 organizaciones y 1155 de ellas completaron todo el cuestionario ${ }^{48}$, aunque es importante matizar que se circunscribe a las instituciones americanas.

Otras investigaciones hablan de ventas directas a través, o gracias a, Instagram. El informe que Artsy realizó a coleccionistas (todos activos en Instagram y con más de 100 obras en sus colecciones de arte) arrojó un dato muy ilustrativo: un $51,5 \%$ de ellos habían comprado obra a artistas que habían descubierto a través de esta plataforma social ${ }^{49}$. Estos coleccionistas no solo buscan novedades en sus artistas habituales, sino que también usan la aplicación para descubrir nuevas firmas y para seguir o descubrir tendencias en el arte, además de crear sus propias preferencias publicando las obras que tienen o que están considerando adquirir ${ }^{50}$.

No es solo una cuestión de oportunidad para ver más obra y comprar más rápidamente, sino que adquirir a través de Instagram implica otras cuestiones como la mejora en la transparencia del comercio de obras. El comprador tiene acceso directo al artista y a toda su obra, cuando en el formato tradicional solo el galerista o intermediario lo tenían, según la opinión del 73\% de los coleccionistas encuestados ${ }^{51}$.

\section{Conclusiones}

Las redes sociales han abierto unas fronteras y ha creado otras, sobre todo las que están apegadas al desarrollo de las TICs y al darwinismo tec- 
nológico ${ }^{52}$. Las redes sociales y otras plataformas digitales son un universo en sí mismo que contiene todo el mundo del arte: creadores, galerías y museos, intermediarios y compradores. También el mundo de la crítica comienza a involucrase en las redes. Todavía son acciones tímidas y no sistematizadas ${ }^{53}$, pero es precisamente la ruptura de los márgenes tradicionales en la creación, difusión y consumo del arte lo que crea nuevas fórmulas para el resto de la industria artística.

Podemos indicar ya algunos márgenes quebrantados. Así, en el ámbito de la creación los artistas elaboran proyectos específicos para la lógica y las fronteras propias de las redes sociales y las relaciones transmedia. El público, a través de la conciencia trasmediática, incide en la evolución y destino de la obra y/o del artista, en un rol muy alejado del espectador pasivo anterior. La difusión que hacen las instituciones de sus colecciones arroja ya números interesantes en el acceso a las piezas, el conocimiento del centro de arte y también en la venta de entradas. Y es en la venta donde quizás se está activando más el uso de las redes, junto con la creación. Como se ha comentado anteriormente Christie's y Sotheby's usan la aplicación de Instagram, pero ya existen también otras plataformas específicas para la venta y subasta de obra como Artsy ${ }^{54} \mathrm{O}$ Invaluable ${ }^{55}$.

Sin embargo, las redes sociales como herramientas de creación, difusión o venta tienen tam- bién voces críticas. Por ejemplo, Julenne Esquinca afirmó sobre Instagram que "aún necesita romper varias barreras, ya que se ha cuestionado la capacidad de esta red social como herramienta de promoción para el arte, sus detractores sostienen que la producción masiva de imágenes complica la lectura de trabajos artísticos ya que se pierden ante la vorágine de imágenes producidas. Además que no es un espacio 'serio' afirman"56. Pero a nuestro entender y tras realizar esta investigación, lo que se desprende del panorama artístico es que hay una batalla muy antigua entre las formas asentadas y las nuevas vías de creación y distribución ya que, de algún modo, se desequilibra el status quo y eso siempre crea conflictos.

No solo la red burbujea con pulsión escópica, sino que lo hace de una forma trasmediática. Entre las nuevas divas icónicas extraídas del imaginario colectivo que se hacen carne y los colectivos de artistas masivos hay toda una industria del arte en las redes que está difuminando todos los roles.

A pesar de esto, es indudable que a las redes sociales les queda un largo camino por recorrer que no tiene solo que ver con ellas mismas sino también con la alfabetización en las tecnologías de la ciudadanía, los sistemas de pago seguro, el acceso a móviles de última generación o las conexiones inalámbricas rápidas, seguras y baratas. 
NOTAS

1 Estas primeras aproximaciones suponen una reflexión conceptual de los cambios que las nuevas tecnologías de interconexión digital y social están permitiendo a los artistas, galeristas, público y en general a todos los actores de las industrias culturales.

${ }^{2}$ Mirzoeff, Nicholas.1999. Una introducción a la cultura visual. Barcelona: Paidós. Espec. "La vida moderna se desarrolla en la pantalla", p. 17.

${ }^{3}$ Ramírez, Juan Antonio. 1976. Medios de masas e historia del arte. Madrid: Cátedra

${ }^{4}$ Lipovetsky, Gilles y Serroy, Jean (2009). La pantalla global: Cultura mediática y cine en la era hipermoderna. Barcelona: Anagrama

${ }^{5}$ Tisseron, Serge. 2000. El misterio de la cámara lúcida: fotografía e inconsciente. Salamanca: Ediciones Universidad de Salamanca.

${ }^{6}$ Ródenas, entre otros, insiste en que se ha "democratizado la experiencia visual y [...] la producción audiovisual". Ródenas, Gabri. 2013. "Capturar es compartir. Filosofía, redes sociales y fotografía 2.0". Enrahonar. Quaderns de Filosofia 50: 59-72. Espec. p. 61

7 Mattei, María Mihela. 2015. "El divinismo en tiempos de \#Instagram". In CIC Cuadernos de Información y Comunicación 20: 95-107. Espec: 95. https://doi.org/10.5209/ rev_CIYC.2015.v20.49385 Consultado por última vez el 20 de mayo de 2018

8 Jenkins, Henry. 2009. "Transmedia Storytelling 101". In Henry Jenkins: http://henryjenkins. org/2007/03/transmedia_storytelling_101.html Última consulta realizada el 20 de mayo de 2018

9 Jenkins, Henry. 2009. "The Revenge of the Origami Unicorn: Seven Principles of Transmedia Storytelling". In Henry Jenkins. http://henryjenkins. org/2009/12/the_revenge_of_the_origami_uni.html Última consulta realizada el 20 de mayo de 2018; y Jenkins, Henry. 2009. "Revenge of the Origami Unicorn: The Remaining Four Principles of Transmedia Storytelling". Henry Jenkins 12 de diciembre, http://henryjenkins.org/2009/12/revenge_of_the_origami_unicorn.html\#sthash.HCrkSsGM. dpuf Última consulta realizada el 23 de mayo de 2018

${ }^{10}$ La web de Pinterest es http:// www. pinterest.com

${ }^{11}$ La web de Instagram es https:// www.instagram.com

${ }^{12}$ La página de Youtube es https:// www.youtube.com

${ }^{13}$ La página web de Artsy es https://www.artsy.net/artists

${ }^{14}$ Jenkins, Henry. 2011. "Transmedia 202: Further Reflections". Henry Jenkins 1 de agosto de 2011. In: http:// henryjenkins.org/2011/08/defining_ transmedia_further_re.html última consulta realizada el 20 de mayo de 2018

${ }^{15}$ Dada la naturaleza espacio-temporal de esta primera aproximación no se ha incluido Youtube en este trabajo, pero es una red que presenta evidente atractivo e interés dentro del mundo del arte, tanto como medio de difusión como material creativo.

${ }^{16}$ Las dos primeras características las definió en Jenkins, Henry. 2009. Op. Cit. "The Revenge of the Origami Unicorn: Seven Principles of Transmedia Storytelling". Las cuatro últimas características se encuentran explicadas en Jenkins, Henry. 2009. Op. Cit. "Revenge of the Origami Unicorn: The Remaining Four Principles of Transmedia Storytelling".

${ }^{17}$ Medina, Manuel. 2007. "Prólogo". In LÉVY, Pierre. Cibercultura. Informe al Consejo de Europa. Barcelona: Anthropos, p. VII.

${ }^{18}$ Ródenas, Gabri, Capturar es compartir, p. 61

${ }^{19}$ En The Bansky Shop se pueden comprar desde camisetas hasta lienzos impresos, o tazas de desayuno. Más información en http://www.thebanksyshop.co.uk/Consultado por última vez el 31 de mayo de 2016.

${ }^{20}$ BBC. 20/08/2015. "Banksy Dismaland show revealed at Weston's Tropicana". In $B B C$, http://www.bbc.co.uk/ news/uk-england-bristol-33999495 Consultado por última vez el 31 de mayo de 2018

${ }^{21}$ Picatoste, María. 5/04/2016. "El arte en los tiempos de Instagram". In Medium.com. https://medium.com/@ pikatoust/el-arte-en-los-tiempos-de- instagram-8b7f70a1b3ba Consultado por última vez el 13 de mayo de 2019

${ }^{22}$ NOSOTROS. s.f. "Nosotros". In Nosotros-art. http://www.nosotros-art. com/nosotros Consultado por última vez el 24 de mayo de 2018

${ }^{23}$ Mattei, El divinismo en tiempos de \#Instagram, p. 96

${ }^{24}$ Kunsthalle Wien. 8/03/2015. "Performance Amalia Ulman 4/3 2015: The Future of Memory". In Youtube, https://www.youtube.com/ watch?v=2ISBUKRcrLQ Consultado por última vez el 31 de mayo de 2018

${ }^{25}$ Sooke, Alastair. 12/01/2016. "Is this the first Instagram masterpiece?". In The Telegraph http://www.telegraph. co.uk/photography/what-to-see/is-thisthe-first-instagram-masterpiece/ Consultado por última vez el 24 de mayo de 2018

${ }^{26} \mathrm{El}$ programa se encuentra en https://www.google.co.uk/url?sa=t \& $r c t=j \& q=\& e s r c=s \&$ source $=$ web $\& c d=$ 1 \&ved=0ahUKEwjtqKacjYTNAhWM LsAKHC2OAK8QFggfMAA\&url=htt p \% 3A\%2F\%2Fwww. newmuseum. org\%2Fpress\%2Fdownload\%2F79\&us $\mathrm{g}=\mathrm{AFQjCNGVNdCamzy0aeb7qf6jWW}$ zXwl74fw\&sig2=kYnj3ztAdfLCHG-d QGbiDA\&bvm =bv. 123325700,d.ZGg Consultado por última vez el 15 de mayo de 2019

${ }^{27}$ Adams, Susan. 4/01/2016. "From Ashley Graham to Lauren Conrad: 30 Under 30 In Art and Style". In Forbes http://www.forbes.com/sites/ susanadams/2016/01/04/from-ashleygraham-to-lauren-conrad-30-under30-in-art-and-style/\#288f97ac380e Consultado por última vez el 24 de agosto de 2018. También Kinsella, Eileen. 4/01/2016. "Outraged Photographer Sues Gagosian Gallery and Richard Prince for Copyright Infringement". In artnetnews https://news.artnet.com/ market/donald-graham-sues-gagosianrichard-prince-401498 Consultado por última vez el 24 de mayo de 2018

${ }^{28}$ Baker (curator). 15/02/2016. "Performing for the Camera: 5 key artista". TATE https://www.tate.org.uk/ whats-on/tate-modern/exhibition/performing-camera Consultado por última vez el 13 de mayo de 2019

${ }^{29}$ Mattei, El divinismo en tiempos de \#Instagram, p. 97 
${ }^{30}$ Ibidem. p. 101

${ }^{31}$ THE INFLUENCERS. s.f. "Amalia Ulman". In The Influencers.org http:// theinfluencers.org/amalia-ulman Consultado por última vez el 24 de mayo de 2018

${ }^{32}$ Se puede ver la galería de esta comunidad creativa en https://www.instagram.com/applifam/ Consultado por última vez el 13 de mayo de 2019

33 Thornton, Leslie-Jean. 2014. "The Photo Is Live at Applifam: An Instagram Community Grapples with How Images Should Be Used". In Visual Communication Quarterly, Routledge, 21:2, p. 72-82 http://dx.doi.org/10.108 0/15551393.2014.928147 Consultado por última vez el 24 de mayo de 2018. Excep: p. 73

${ }^{34}$ MUSEUMS AND THE WEB. 2015. "\#MobilePhotoNow Instagram Exhibition at Columbus Museum of Art". In 19th annual Museums and the Web conference annual conference http:// mw2015.museumsand theweb.com/ bow/mobilephotonow-instagram-exhibition-at-columbus-museum-of-art/ Consultado por última vez el 25 de mayo de 2016

${ }^{35}$ CANADIAN HERITAGE INFORMATION NETWORK. 2013. "Museums Invite Instagrammers to Participate in Exhibits". In Canada Government.ca http:// www.rcip-chin.gc.ca/sgc-cms/nouvelles-news/anglais-english/? $p=6350$ Consultado por última vez el 13 de mayo de 2019

${ }^{36}$ Marcelino, Georgina y Morena, Marián. 2014. "Redes sociales basadas en imágenes como herramienta de comunicación museística. Museos y centros de arte Moderno y Contemporáneo de España en Pinterest e Instagram". In adComunica. Revista Científica de Estrategias, Tendencias e Innovación en Comunicación 8, p: 139-167. Espec: p.160 http://www.adcomunicarevista. com/ojs/index.php/adcomunica/article/ view/202 Consultado por última vez el 13 de mayo de 2019

${ }^{37}$ EP. 4/03/2015. "El arte de Instagram se instala en la Sala Fundación Cruzcampo". In La Opinión de Málaga http://www.laopiniondemalaga.es/cultura-espectaculos/2015/03/03/andalucia-malaga--cultura-/748011.html Con- sultado por última vez el 15 de mayo de 2019

38 INSTAGRAMERS. (s.f.). "About". In Instagramers.com, http://instagramers.com/about/ Consultado por última vez el 15 de mayo de 2019

${ }^{39}$ Rivera, Patricia. 2/01/2014. "Cuando Instagram se hace arte". In El Mundo http://www.elmundo.es/yo dona/2013/12/30/52aef46722601d4c of8b4594.html Consultado por última vez el 25 de mayo de 2018

${ }^{40}$ Más información sobre la app http://lucaslevitan.com/category/theapp/ Consultado por última vez el 25 de mayo de 2016.

${ }^{41}$ Gonzalez afirma que la "Instagramers gallery is a big success until now, and after 6 months of exhibition on the second floor at Fundación Telefónica it has been moved to the ground floor at the entrance of the building. Now you can have a coffee, a drink, a healthy salad.....and see the selection of photographs of our mobile Instagramers Team and other temporary exhibitions from contest winners." González, Phil. 13/10/2014. "Welcome to the new Instagramers Gallery in Madrid!". In Instagramers.com, htp://instagramers. com/destacados/welcome-to-the-newinstagramers-gallery-in-madrid/ Consultado por última vez el 13 de mayo de 2019.

${ }^{42}$ Más información sobre este proyecto en https://www.artsy.net/ Consultado por última vez el 15 de mayo de 2019

${ }^{43}$ En el año 2014 Instagram ya superaba en usuarios a Twitter según el especialista Gelles, David. 19/12/2014. "Citigroup Says Instagram Is Worth $\$ 35$ Billion". In The New Yoirk Times http:// dealbook.nytimes.com/2014/12/19/ citigroup-says-instagram-is-worth35-billion/?_r=2\&utm_source=Artsy+ Gallery+Insights+\%28new\%29\&utm_ campaign=966cca4147-2015_4_20_ Artsy_Gallery_Insights_4\&utm_ m e di u m = e m a i I\&ut m _ term=0_95ac2900c4-966cca4147Consultado por última vez el 26 de mayo de 2018

${ }^{44}$ Thomson, Kristin, Purcell, Kristen, y Rainie, Lee. 2013. Arts Organizations and Digital Technologies. Washington: Pew Research Center's Internet
\& American Life Project, pp. 1-65. Excep: p. 26 https://www.pewinternet. org/2013/01/04/arts-organizationsand-digital-technologies/ Consultado por última vez el 13 de mayo de 2019

${ }^{45}$ Esquinca, Julenne. 16/08/2015. "Instagram ¿Herramienta para la venta de arte?", Fahrenheit Magazine, http:// fahrenheitmagazine.com/vidaestilo/tecnologia/instagram-herramienta-para-laventa-de-arte/ Consultado por última vez el 26 de mayo de 2018 [en la actualidad fuera de línea]

${ }^{46}$ Para Thomson et.al: "Increased attendance at events, More ticket sales, Increased public awareness of the organization, An ability to support fundraising efforts" en Thomson, Kristin, Purcell, Kristen, y Rainie, Lee, Arts Organizations, p. 4.

47 "Mobile connectivity is beginning to drive some activity in arts organizations. Some $24 \%$ of these respondents say they use apps to provide content to the public; $17 \%$ say they use apps to facilitate work in their own organization; $15 \%$ use apps to sell tickets or services; $5 \%$ use apps to train and educate employees". Ibidem.

\section{${ }^{48}$ Ibidem.}

${ }^{49}$ Soboleva, Elena. 19/04/2015. "How Collectors Use Instagram to Buy Art". In Artsy.net https://www.artsy.net/ article/elena-soboleva-collectors-instagram-to-buy-art Consultado por última vez el 15 de mayo de 2019

50 "Collectors also rely on Instagram as a tool for discovering and researching art trends. While $30 \%$ post the works they are considering acquiring for their collection, many others use it to gauge current trends. It is hype for sure, which has negative and positive effects. But if your artwork isn't represented on Instagram these days, do you exist? - NY Collector". Ibidem

\section{Ibidem}

52 Pérez, Johanna. 2015. "Fotografía en tiempos de darwinismo tecnológico". In Aularia 1, pp. 9-14 http:// www.aularia.org/ContadorArticulo. php?idart=175 Consultado por última vez el 26 de mayo de 2016

${ }^{53}$ Enlazo a continuación los resultados del rastreo de Google Trends respecto a "practical art critic". Los resultados fueron los mismos con 
búsquedas similares como "art critic": https://trends.google.com/trends/ explore cat $=299 \&$ date $=$ today $\% 20$ $5-y \& q=\% 2 F m \% 2 F 0 g \mid p j l l$,Practical\%20 art\%20criticism, \%2Fm\%2F0jjw Bús- queda realizada el 26 de mayo de 2016 y actualizada el 15 de mayo de 2019

${ }^{54}$ Para visitar su web clicar en https://www.artsy.net/ Consultado por última vez el 26 de mayo de 2016
${ }_{55}$ Para visitar su web clicar en http:// www.invaluable.com/ Consultado por última vez el 26 de mayo de 2016

${ }^{56}$ Esquinca, Julenne, 16/08/2015, "Instagram...", s/n. 


\section{REFERENCIAS}

Adams, Susan. 4/01/2016. "From Ashley Graham to Lauren Conrad: 30 Under 30 In Art and Style." In Forbes http://www.forbes.com/ sites/susanadams/2016/01/04/from-ashleygraham-to-lauren-conrad-30-under-30-inart-and-style/\#288f97ac380e Consultado por última vez el 24 de agosto de 2018.

Baker (curator). 15/02/2016. "Performing for the Camera: 5 key artista." TATE https://www. tate.org.uk/whats-on/tate-modern/exhibition/ performing-camera Consultado por última vez el 13 de mayo de 2019

BBC. 20/08/2015. "Banksy Dismaland show revealed at Weston's Tropicana." In $B B C$, http://www.bbc.co.uk/news/uk-england-bristol-33999495 Consultado por última vez el 31 de mayo de 2018

CANADIAN HERITAGE INFORMATION NETWORK. 2013. "Museums Invite Instagrammers to Participate in Exhibits." In Canada Government.ca http://www.rcip-chin.gc.ca/sgc-cms/nouvellesnews/anglais-english/? $\mathrm{p}=6350$ Consultado por última vez el 13 de mayo de 2019

EP. 4/03/2015. "El arte de Instagram se instala en la Sala Fundación Cruzcampo." In La Opinión de Málaga http://www.laopiniondemalaga.es/ cultura-espectaculos/2015/03/03/andaluciamalaga--cultura-/748011.html Consultado por última vez el 15 de mayo de 2019

Esquinca, Julenne. 16/08/2015. "Instagram ¿Herramienta para la venta de arte?" Fahrenheit Magazine, http://fahrenheitmagazine.com/ vidaestilo/tecnologia/instagram-herramientapara-la-venta-de-arte/ Consultado por última vez el 26 de mayo de 2018 [en la actualidad fuera de línea].

Gelles, David. 19/12/2014. "Citigroup Says Instagram is Worth \$35 Billion." In The New York Times http://dealbook.nytimes. com/2014/12/19/citigroup-says-instagramis-worth-35-billion/?_r=2\&utm_source= Artsy+Gallery+Insights+\%28new\%29\&u tm_campaign=966cca4147-2015_4_20_ Artsy_Gallery_Insights_4\&utm_ medium=email\&utm_term=0_95ac2900c4- 966cca4147- Consultado por última vez el 26 de mayo de 2018.

González, Phil. 13/10/2014. "Welcome to the new Instagramers Gallery in Madrid!" In Instagramers.com http://instagramers.com/destacados/welcome-to-the-new-instagramersgallery-in-madrid/ Consultado por última vez el 13 de mayo de 2019.

INSTAGRAMERS. (s.f.). "About." In Instagramers. com, http://instagramers.com/about/ Consultado por última vez el 15 de mayo de 2019

Jenkins, Henry. 2011. "Transmedia 202: Further Reflections." In Henry Jenkins 1 de agosto de 2011. In: http://henryjenkins.org/2011/08/ defining_transmedia_further_re.html última consulta realizada el 20 de mayo de 2018

Jenkins, Henry. 2009. "Transmedia Storytelling 101." In Henry Jenkins: http://henryjenkins.org/2007/03/transmedia_storytelling_101.html última consulta realizada el 20 de mayo de 2018

Jenkins, Henry. 2009. "The Revenge of the Origami Unicorn: Seven Principles of Transmedia Storytelling." In Henry Jenkins. http://henryjenkins.org/2009/12/the_revenge_of_the_ origami_uni.html última consulta realizada el 20 de mayo de 2018.

Jenkins, Henry. 2009. "Revenge of the Origami Unicorn: The Remaining Four Principles of Transmedia Storytelling." Henry Jenkins 12 de diciembre, http://henryjenkins. org/2009/12/revenge_of_the_origami_unicorn.html\#sthash.HCrkSsGM.dpuf última consulta realizada el 23 de mayo de 2018

Kinsella, Eileen. 4/01/2016. "Outraged Photographer Sues Gagosian Gallery and Richard Prince for Copyright Infringement." In artnetnews https://news.artnet.com/market/donaldgraham-sues-gagosian-richard-prince-401498 Consultado por última vez el 24 de mayo de 2018

Kunsthalle Wien. 8/03/2015. "Performance Amalia Ulman 4/3 2015: The Future of Memory." In Youtube, https://www.youtube. com/watch?v=2ISBUKRcrLQ Consultado por última vez el 31 de mayo de 2018 
Lipovetsky, Gilles, y Jean Serroy. 2009. La pantalla global: Cultura mediática y cine en la era hipermoderna. Barcelona: Anagrama. https:// doi.org/10.7764/cdi.24.61

Mannix, Hyatt. 2014. New Museum And Rhizome to Copresent First Look A Series Of Projects Showcasing Art On The Net. Available at https://www.google.co.uk/url?sa=t\&rct=j\&q= \&esrc $=$ s\&source $=$ web $\& c d=1 \&$ ved $=0$ ahUKEw jtqKacjYTNAhWMLsAKHc2OAK8QFggfMAA \&url=http \%3A\%2F\%2Fwww.newmuseum. org \%2Fpress\%2Fdownload\%2F79\&usg=AF QjCNGVNdCamzy0aeb7qf6jWWzXwl74fw\& sig2=kYnj3ztAdfLCHG-dQGbiDA\&bvm=bv. 1 23325700,d.ZGg Consultado por última vez el 15 de mayo de 2019

Marcelino, Georgina, y Marián Morena. 2014. "Redes sociales basadas en imágenes como herramienta de comunicación museística. Museos y centros de arte Moderno y Contemporáneo de España en Pinterest e Instagram." In adComunica. Revista Científica de Estrategias, Tendencias e Innovación en Comunicación 8: 139-167. http://www.adcomunicarevista.com/ojs/index.php/adcomunica/article/ view/202 Consultado por última vez el 13 de mayo de 2019. https://doi.org/10.6035/21740992.2014.8.9

Mattei, María Mihela. 2015. “El divinismo en tiempos de \#Instagram." In CIC Cuadernos de Información y Comunicación 20: 95-107. https://doi.org/10.5209/rev_CIYC.2015. v20.49385 Consultado por última vez el 20 de mayo de 2018. https://doi.org/10.5209/ rev_ciyc.2015.v20.49385

Medina, Manuel. 2007. "Prólogo." Cibercultura. Informe al Consejo de Europa, Pierre Lévy, VII. Barcelona: Anthropos.

Mirzoeff, Nicholas.1999. Una introducción a la cultura visual. Barcelona: Paidós.

MUSEUMS AND THE WEB. 2015. "\#MobilePhotoNow Instagram Exhibition at Columbus Museum of Art." In 19th annual Museums and the Web conference annual conference http://mw2015. museumsandtheweb.com/ bow/mobilephotonow-instagram-exhibitionat-columbus-museum-of-art/ Consultado por última vez el 25 de mayo de 2016
NOSOTROS. s.f. "Nosotros." In Nosotros-art. http://www.nosotros-art.com/nosotros Consultado por última vez el 24 de mayo de 2018.

Pérez, Johanna. 2015. “Fotografía en tiempos de darwinismo tecnológico." In Aularia 1: 9-14 http://www.aularia.org/ContadorArticulo. php?idart=175 Consultado por última vez el 26 de mayo de 2016

Picatoste, María. 5/04/2016. “El arte en los tiempos de Instagram." In Medium.com. https:// medium.com/@pikatoust/el-arte-en-los-tiempos-de-instagram-8b7f70a1b3ba Consultado por última vez el 13 de mayo de 2019. https:// doi.org/10.13184/eidon.40.2013.71-88

Ramírez, Juan Antonio. 1976. Medios de masas e historia del arte. Madrid: Cátedra

Rivera, Patricia. 2/01/2014. "Cuando Instagram se hace arte." In El Mundo http://www.elmundo.es/yodona/2013/12/30/52aef46722601d4 c0f8b4594.html Consultado por última vez el 25 de mayo de 2018

Ródenas, Gabri. 2013. "Capturar es compartir. Filosofía, redes sociales y fotografía 2.0." Enrahonar. Quaderns de Filosofia 50: 5972. https://doi.org/10.5565/rev/enrahonar/ v50n0.116

Soboleva, Elena. 19/04/2015. "How Collectors Use Instagram to Buy Art." In Artsy.net https://www.artsy.net/article/elena-sobolevacollectors-instagram-to-buy-art Consultado por última vez el 15 de mayo de 2019

Sooke, Alastair. 12/01/2016. "Is this the first Instagram masterpiece?" In The Telegraph http:// www.telegraph.co.uk/photography/what-tosee/is-this-the-first-instagram-masterpiece/ Consultado por última vez el 24 de mayo de 2018

The Bansky Shop. 2016. http://www.thebanksyshop.co.uk/ Consultado por última vez el 31 de mayo de 2016

THE INFLUENCERS. s.f. "Amalia Ulman." In The Influencers.org http://theinfluencers.org/amalia-ulman Consultado por última vez el 24 de mayo de 2018 
La industria artística en el entorno transmedia de las redes sociales. Primeras aproximaciones

Tisseron, Serge. 2000. El misterio de la cámara lúcida: fotografía e inconsciente. Salamanca: Ediciones Universidad de Salamanca.

Thornton, Leslie-Jean. 2014. "The Photo Is Live at Applifam: An Instagram Community Grapples with How Images Should Be Used" In Visual Communication Quarterly 21 (2): 7282 http://dx.doi.org/10.1080/15551393.201 4.928147 Consultado por última vez el 24 de mayo de 2018. https://doi.org/10.1080/1555 1393.2014.928147

Thomson, Kristin, Purcell, Kristen, and Lee Rainie. 2013. Arts Organizations and Digital Technologies. Washington: Pew Research Center's Internet \& American Life Project, 1-65. https:// www.pewinternet.org/2013/01/04/arts-orga- nizations-and-digital-technologies/ Consultado por última vez el 13 de mayo de 2019

\section{Sitios web y aplicaciones}

- AppLifam https://www.instagram.com/applifam/

- Artsy https://www.artsy.net/artists

- Instagram https://www.instagram.com

- Invaluable http://www.invaluable.com/

- Lucas Levitan http://lucaslevitan.com/category/ the-app/

- Pinterest http://www.pinterest.com

- Youtube https://www.youtube.com 